\title{
Technical note: Update on response times, in-air measurements, and in situ drift for oxygen optodes on profiling platforms
}

\author{
Henry C. Bittig ${ }^{1}$ and Arne Körtzinger ${ }^{2,3}$ \\ ${ }^{1}$ Sorbonne Universités, UPMC Université Paris 06, CNRS, UMR 7093, Laboratoire d'Océanographie \\ de Villefranche (LOV), Villefranche-sur-Mer, France \\ ${ }^{2}$ GEOMAR Helmholtz-Zentrum für Ozeanforschung Kiel, Kiel, Germany \\ ${ }^{3}$ Christian-Albrechts-Universität zu Kiel, Kiel, Germany \\ Correspondence to: Henry C. Bittig (bittig@obs-vlfr.fr)
}

Received: 14 September 2016 - Published in Ocean Sci. Discuss.: 29 September 2016

Revised: 15 December 2016 - Accepted: 20 December 2016 - Published: 13 January 2017

\begin{abstract}
Oxygen optode measurements on floats and gliders suffer from a slow time response and various sources of drift in the calibration coefficients. Based on two dual$\mathrm{O}_{2}$ Argo floats, we show how to post-correct for the effect of the optode's time response and give an update on optode in situ drift stability and in-air calibration. Both floats are equipped with an unpumped Aanderaa 4330 optode and a pumped Sea-Bird SBE63 optode. Response times for the pumped SBE63 were derived following Bittig et al. (2014) and the same methods were used to correct the time response bias. Using both optodes on each float, the time response regime of the unpumped Aanderaa optode was characterized more accurately than previously possible. Response times for the pumped SBE63 on profiling floats are in the range of 25-40 s, while they are between 60 and $95 \mathrm{~s}$ for the unpumped 4330 optode. Our parameterization can be employed to post-correct the slow optode time response on floats and gliders. After correction, both sensors agree to within 2$3 \mu \mathrm{mol} \mathrm{kg}{ }^{-1}$ (median difference) in the strongest gradients $\left(120 \mu \mathrm{mol} \mathrm{kg}^{-1}\right.$ change over $8 \mathrm{~min}$ or $\left.20 \mathrm{dbar}\right)$ and better elsewhere. However, time response correction is only possible if measurement times are known, i.e., provided by the platform as well as transmitted and stored with the data. The $\mathrm{O}_{2}$ in-air measurements show a significant in situ optode drift of -0.40 and $-0.27 \% \mathrm{yr}^{-1}$ over the available 2 and 3 years of deployment, respectively. Optode in-air measurements are systematically biased high during midday surfacings compared to dusk, dawn, and nighttime. While preference can be given to nighttime surfacings to avoid this in-air calibration bias, we suggest a parameterization of the daytime effect as
\end{abstract}

a function of the Sun's elevation to be able to use all data and to better constrain the result. Taking all effects into account, calibration factors have an uncertainty of $0.1 \%$. In addition, in-air calibration factors vary by $0.1-0.2 \%$ when using different reanalysis models as a reference. The overall accuracy that can be achieved following the proposed correction routines is better than $1 \mu \mathrm{mol} \mathrm{kg}{ }^{-1}$.

\section{Introduction}

While oceanic oxygen measurements of the last century were mostly based on Winkler titrations of discrete water samples or profiles acquired with CTD-mounted electrochemical oxygen sensors, such observations rely increasingly on $\mathrm{O}_{2}$ optode sensors (Tengberg et al., 2006) deployed on autonomous platforms. In particular, the planning for a global Biogeochemical-Argo observation network of profiling floats equipped with biogeochemical sensors (including $\mathrm{O}_{2}$ optodes) is well under way (Johnson and Claustre, 2016) and the use of gliders is becoming more operational (e.g., EGO: Testor et al., 2012).

Apart from cost effectiveness, the main reasons for this are improved sensor performance and characterization with respect to temperature and $\mathrm{O}_{2}$ response (e.g., Bittig et al., 2012), hydrostatic pressure (Uchida et al., 2008; Bittig et al., 2015a), time response (Bittig et al., 2014), and $\mathrm{O}_{2}$ drift behavior (D'Asaro and McNeil, 2013; Bittig and Körtzinger, 2015; Bushinsky et al., 2016) as well as improved accuracy, either through in-air measurements during deployment or 
careful pre-/post-deployment calibrations for short deployments, e.g., of gliders.

It is therefore timely and useful to revisit the foundations of both pumped and unpumped $\mathrm{O}_{2}$ optode behavior on autonomous, profiling platforms, to ensure optimal data postprocessing and best data quality. In this technical note, we want to refine the findings of Bittig et al. (2014) on the optode time response and of Bittig and Körtzinger (2015) on in-air measurements and in situ drift stability.

\section{Instrument description}

This study utilizes data from two dual- $\mathrm{O}_{2}$ Navis floats (SeaBird Inc., Bellevue, USA) with WMO ID 6900889 and 6900890 that were deployed in the eastern tropical North Atlantic in the oxygen minimum zone in November 2014 and September 2013, respectively. Each float is equipped with two $\mathrm{O}_{2}$ optodes, an unpumped Aanderaa 4330 optode (AADI, Bergen, Norway) and a pumped SBE63 optode (SeaBird Inc., Bellevue, USA). Aanderaa 4330 optodes have been pre-aged at the factory and were equipped with the standard foil with optical isolation. For each float, the optodes were laboratory-calibrated in the same calibration run (following Bittig et al., 2012) prior to deployment.

Only the unpumped Aanderaa 4330 optode, cablemounted in an elevated position on the float's top cap, is capable of in-air measurements, and the float's firmware was adjusted accordingly (see Bittig and Körtzinger, 2015, for details). In addition, the Navis floats transmitted a time stamp for each profile sample (i.e., each set of pressure, temperature, salinity, and optode raw data), through which only the time response analysis below was feasible. Since the Aanderaa optodes were mounted close to the floats' pumpedflow CTD intake, respectively, no additional compensation for a vertical pressure offset or a time delay was performed. A third float (WMO ID 6900891) was deployed in the South Pacific oxygen minimum zone off Peru in October 2015, but was trapped inactive near the surface for 5 weeks due to excess air in its air bladder before deployment. It eventually descended and started its mission, but the optodes failed after the first 30 profiles, so it was not included in the analysis.

\section{Time response}

Bittig et al. (2014) used a set of laboratory experiments to validate a two-layer diffusional model of optode time response. In essence, water flow determines the liquid boundary layer thickness, $l_{\mathrm{L}}$, in front of the optode's sensing foil, which is essentially independent of temperature. Temperature, however, modifies the $\mathrm{O}_{2}$ solubility and diffusivity both in the boundary layer and sensing foil, such that the optode's response time, $\tau$, shows a marked temperature dependence (at constant flow $/ l_{\mathrm{L}}$ ), being slower at low temperatures.
Shipboard CTD-O 2 casts with optodes, as well as glider and float data in different ocean regions, served Bittig et al. (2014) to characterize the response time $\tau$ as well as the flow $/ l_{\mathrm{L}}$ regime on these profiling platforms. However, while the shipboard casts had both a fast CTD-O ${ }_{2}$ sensor and an $\mathrm{O}_{2}$ optode on the same platform, the floats and gliders featured only a single optode and relied on a match of the optode data to a "nearby" CTD-O 2 profile. This match introduced some uncertainty into the analysis of Bittig et al. (2014). Using the dual- $\mathrm{O}_{2}$ floats of the present study, the response time and boundary layer regime of optodes on slowly profiling platforms can be constrained far more tightly with the same methods.

Since the SBE63 optode's sensing foil is contained inside the pumped path of the float's CTD, its water flow is set by the pump speed of the float CTD, i.e., ca. $600 \mathrm{~mL} \mathrm{~min}^{-1}$ (Sea-Bird Electronics, 2016). This flow rate corresponds to a boundary layer thickness $l_{\mathrm{L}}$ around $34 \mu \mathrm{m}$ (Bittig et al., 2014, see also Appendix A, Eq. A4). The Aanderaa optode, however, is exposed to the ambient seawater, and the flow in front of its sensing foil varies as a function of the platform's movement. Its flow (and thus its time response) is generally slower than for the pumped SBE63 optode.

Using the faster SBE63 optode $\mathrm{O}_{2}$ as a reference, the 4330 optode time response can be derived relative to the SBE63 optode. However, since the SBE63 optode's time response is well defined $( \pm 3 \mathrm{~s})$ due to the pumped mode of operation, the results of Bittig et al. (2014) can be used to reconstruct a "true" time response-unbiased $\mathrm{O}_{2}$ profile as a reference. The 4330 optode time response can then be derived relative to that reference $\mathrm{O}_{2}$ profile. Both approaches yield equivalent results, and only the second one is shown below. Reconstruction of the unbiased $\mathrm{O}_{2}$ profile is carried out as follows (see also the Appendix and Supplement):

- define the flow regime for the pumped SBE63 optode, i.e., $l_{\mathrm{L}}=34 \mu \mathrm{m}$;

- translate the flow regime into a response time constant $\tau$ using the in situ temperature and data from Fig. 11 in Bittig et al. (2014) (see also the Supplement);

- obtain the mean of consecutive data points of the unbiased $\mathrm{O}_{2}$ profile from the SBE63 optode measurements using the inverse of the filter's bilinear transformation, i.e., Eq. (37) from Bittig et al. (2014) (Eq. A3); and

- reconstruct the unbiased $\mathrm{O}_{2}$ profile by interpolating the mean of consecutive data points of the unbiased $\mathrm{O}_{2}$ profile to the original measurement times.

The analysis of the Aanderaa 4330 optode flow regime behavior takes the opposite approach by filtering or "delaying" the reference $\mathrm{O}_{2}$ profile until it matches the 4330 optode observations. For this, the forward filter (Eqs. 4 and 5 in Bittig et al., 2014, see also Eqs. A1 and A2) was applied to a short 


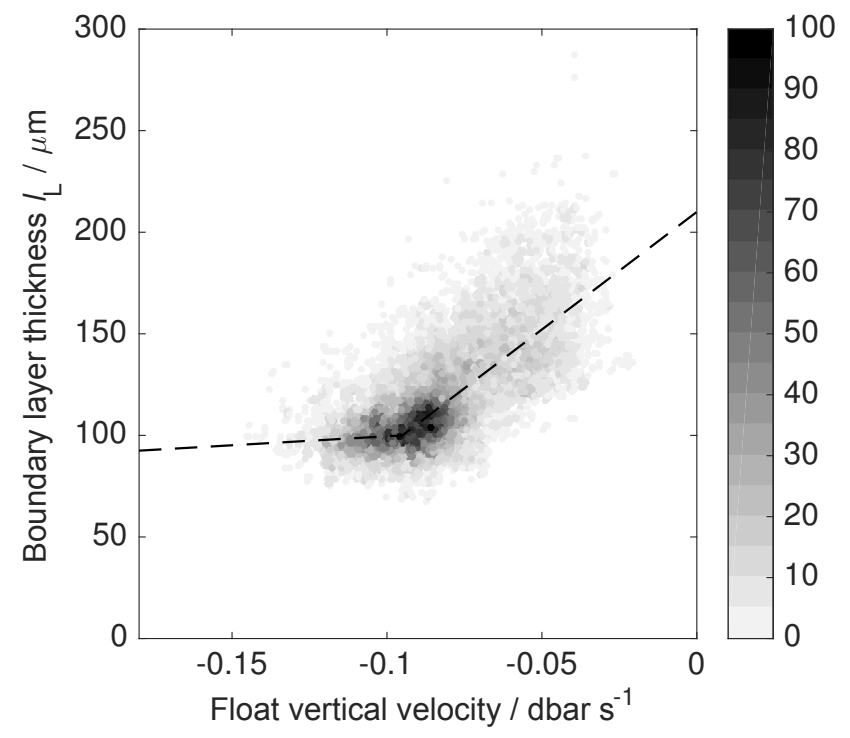

Figure 1. Boundary layer thickness $l_{\mathrm{L}}$ vs. float vertical velocity for an Aanderaa optode 4330 with standard foil derived from dual- $\mathrm{O}_{2}$ floats 6900889 and 6900890 . The color shading indicates the data density, while the dashed line gives the parameterization of Eq. (1).

interval of the unbiased $\mathrm{O}_{2}$ profile and $l_{\mathrm{L}}$ iteratively adjusted. The steps involved are essentially the following:

- estimate a boundary layer thickness $l_{\mathrm{L}}$ for the given short interval of measurements (here: 12 consecutive data points);

- translate $l_{\mathrm{L}}$ into a response time constant $\tau$ using the in situ temperature and data from Fig. 11 in Bittig et al. (2014) (see also the Supplement);

- translate $\tau$ into the filter constants $a$ and $b$ using the measurement times $t_{i}$ and Eq. (4) from Bittig et al. (2014) (Eq. A1);

- apply the recursive filter to the mean of consecutive data points of the unbiased $\mathrm{O}_{2}$ profile and the previous (or initial) filtered $\mathrm{O}_{2}$ measurement (Eqs. 4 and 5 in Bittig et al., 2014) (Eqs. A1 and A2); and

- compare the filtered $\mathrm{O}_{2}$ profile with the Aanderaa 4330 optode measurements and iteratively refine the chosen boundary layer thickness $l_{\mathrm{L}}$ for the given short interval until a best match is achieved.

Overall, the resulting boundary layer thickness $l_{\mathrm{L}}$ is smaller than estimated by Bittig et al. (2014). $l_{\mathrm{L}}$ decreases with increased flow at the sensor, as expected (Fig. 1). Specifically, $l_{\mathrm{L}}$ is around $210 \mu \mathrm{m}$ at $0 \mathrm{dbar} \mathrm{s}^{-1}$ and $100 \mu \mathrm{m}$ at $0.095 \mathrm{dbars}^{-1}$. However, there appears to be a lower limit or regime shift at speeds higher than $0.1 \mathrm{dbar} \mathrm{s}^{-1}$, likely reflecting the transition between laminar and turbulent flow at the sensing foil. From CTD applications, Bittig et al. (2014) found a $l_{\mathrm{L}}$ around $20 \mu \mathrm{m}$ at $1.0 \mathrm{dbars}^{-1}$ when the flow was directed approx. perpendicular to the optode sensing foil (as is typically the case for floats). For other CTD applications with the flow passing tangentially along the optode (similar to typical glider optode attachments), $l_{\mathrm{L}}$ was close to $40 \mu \mathrm{m}$ at $1.0 \mathrm{dbars}^{-1}$ (Bittig et al., 2014). Using these end members, we chose a piecewise linear interpolation to parameterize the flow regime $/ l_{\mathrm{L}}$ vs. platform speed $v$ for floats (Eq. 1). For gliders, we suggest Eq. (2), accordingly.

$l_{\mathrm{L}}$ (float) $/ \mu \mathrm{m}=$

$\begin{cases}210-\frac{110}{0.095} \cdot\left|v / \mathrm{dbar} \mathrm{s}^{-1}\right| & |v| \leq 0.095 \mathrm{dbar} \mathrm{s}^{-1} \\ 20+\frac{80}{0.905} \cdot\left(1-\left|v / \mathrm{dbar} \mathrm{s}^{-1}\right|\right) & |v|>0.095 \mathrm{dbar} \mathrm{s}^{-1}\end{cases}$

$l_{\mathrm{L}}($ glider $) / \mu \mathrm{m}=$

$\begin{cases}210-\frac{110}{0.005} \cdot\left|v / \mathrm{dbar} \mathrm{s}^{-1}\right| & |v| \leq 0.095 \mathrm{dbar} \mathrm{s}^{-1} \\ 40+\frac{60}{0.905} \cdot\left(1-\left|v / \mathrm{dbar} \mathrm{s}^{-1}\right|\right) & |v|>0.095 \mathrm{dbar} \mathrm{s}^{-1}\end{cases}$

This flow regime characterization can now be used to reconstruct a time response-unbiased $\mathrm{O}_{2}$ profile from the Aanderaa 4330 optode the same way as for the SBE63 optode. It must be stressed, however, that all time response corrections need to be done on a time axis ("time series"), not on a pressure axis ("depth profile"). It is therefore important that a time stamp is logged with each optode measurement.

An example of such a reconstruction is shown in Fig. 2, while Fig. 3 illustrates the time response effect. Both floats were deployed in a tropical region with a strong thermocline and consequently pycnocline (Figs. 3a and 2). The density structure determines the floats' ascent velocity and the float slows down significantly in the main thermocline and pycnocline around $50 \mathrm{dbar}$ (Fig. 3b). At intermediate and deep depths, a stable density structure seems to cause the float's buoyancy adjustments (i.e., a change in oil bladder volume to keep a certain ascent velocity) to occur at similar depths for all profiles, which creates the wavelike fluctuations in the median float velocity. Moreover, the $l_{\mathrm{L}}-v$ dependence regime transition at $0.095 \mathrm{dbar} \mathrm{s}^{-1}$ is close to the median float velocity. Observations faster than this threshold have an $l_{\mathrm{L}}$ of essentially $100-110 \mu \mathrm{m}$, while observations at slower velocities show a marked $v$ dependence (compare Fig. 1). This is mirrored in the boundary layer thickness of the unpumped 4330 optode (not shown) and in its response time (Fig. 3c). The slowdown in the main pycnocline causes a $50 \%$ increase in response time of the 4330 optode (from 60 to $95 \mathrm{~s}$ ), while the pumped SBE63 optode remains unaffected (ca. 25-30 s). Superimposed onto the flow effect, cold temperatures at depth cause an increase in $\tau$ (Fig. 3c and d). It is important to note that $\tau$ is much better constrained for the pumped SBE63 optode than for the unpumped 4330 optode.

As expected, the time response correction for the pumped SBE63 optode with small response times changes the $\mathrm{O}_{2}$ data only to some extent (median absolute difference in the strongest gradient: $6-7 \mu \mathrm{mol} \mathrm{kg}{ }^{-1}$; Fig. $3 \mathrm{~h}$ ) and is much more important for the unpumped 4330 optode with larger re- 


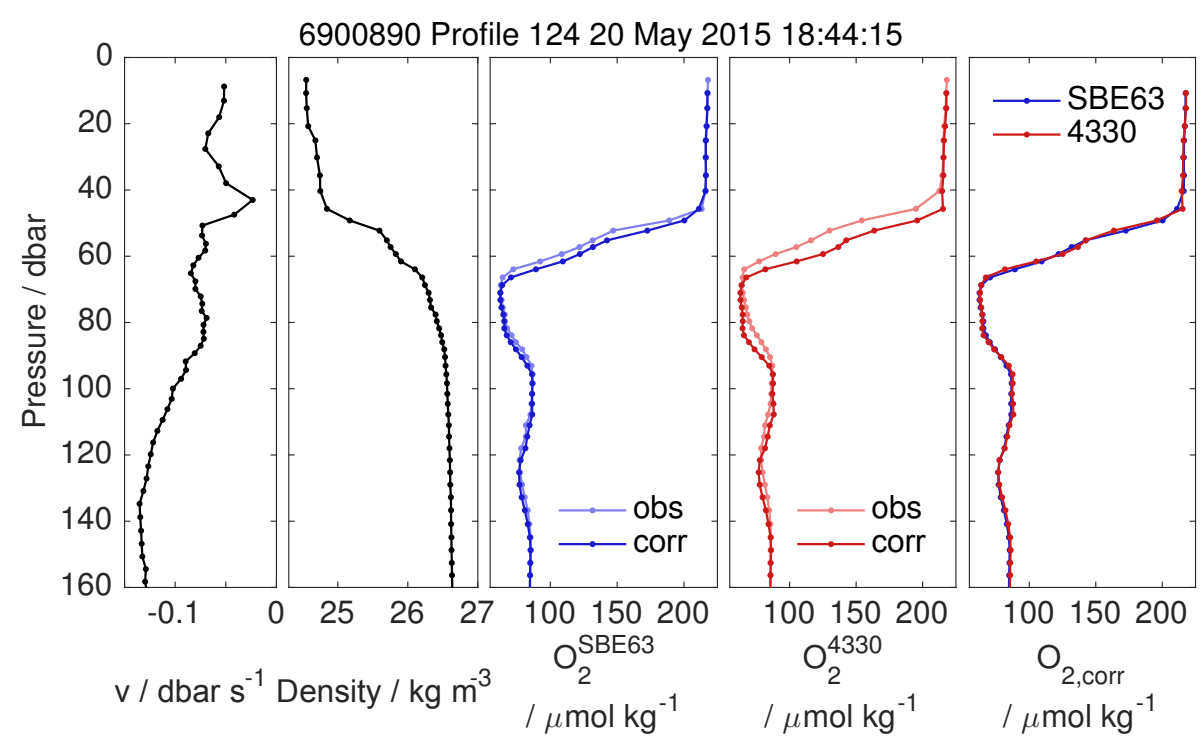

Figure 2. Profiles of ascent speed, density, SBE63 optode $\mathrm{O}_{2}, 4330$ optode $\mathrm{O}_{2}$, and time response-corrected $\mathrm{O}_{2}$ (left to right; the outer right panel shows the superposition of corrected $\mathrm{O}_{2}$ for the SBE63 and 4330 optodes from the previous panels) for float 6900890, cycle 0124. The main oxycline coincides with the pycnocline and the float slows down significantly around 50 dbar, giving the $\mathrm{O}_{2}$ optodes time to adjust. After correction, both sensors agree well in the profile fine structure and the depth of the oxycline, while they diverge before. The time response effect is more pronounced in regions with a weaker density gradient.
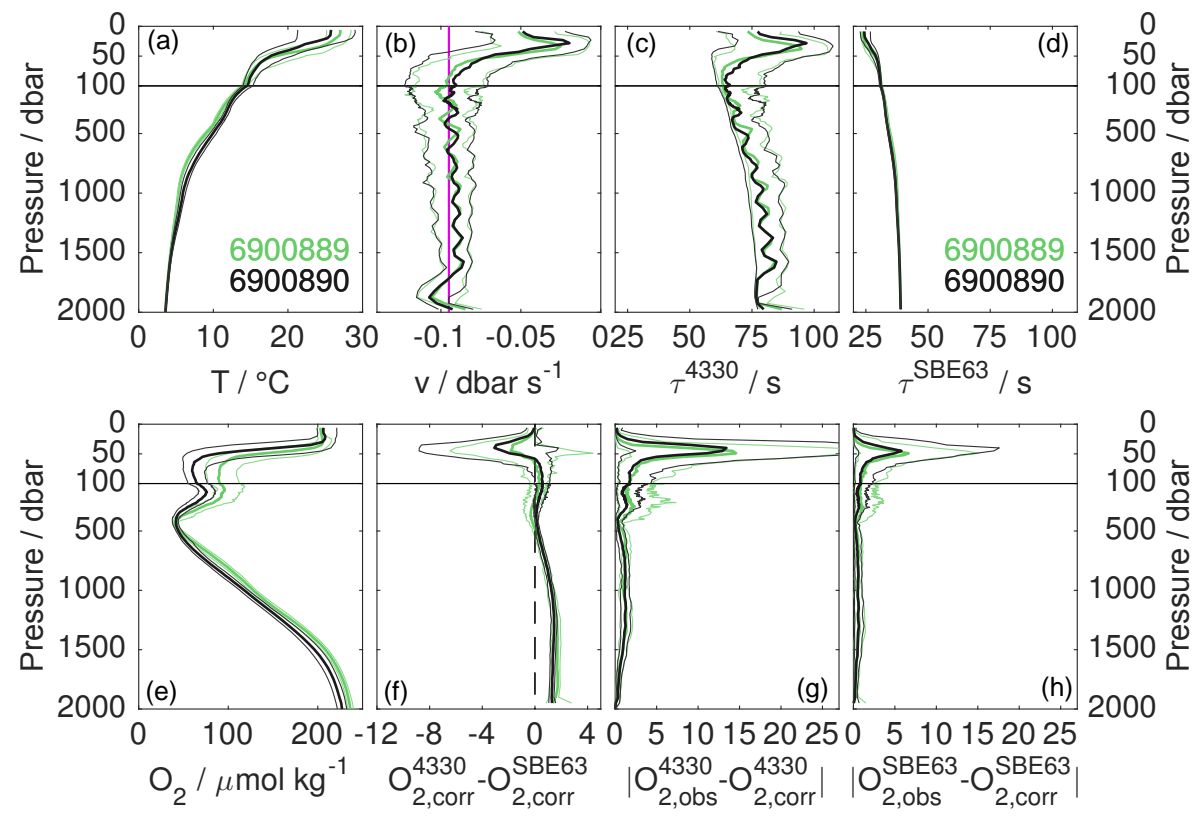

Figure 3. Median profiles (thick lines) with 10th/90th percentiles (thin lines) for floats 6900889 (green) and 6900890 (black): (a) temperature, (b) ascent velocity with $l_{\mathrm{L}}$ vs. $v$ regime transition (Eq. 1) in purple, (c) response time $\tau$ of the Aanderaa 4330 optode, (d) response time $\tau$ of the SBE63 optode, (e) oxygen profile, (f) difference between the time response-corrected 4330 optode and $\mathrm{SBE} 3$ optode $\mathrm{O}_{2}$ as a measure of sensor agreement after correction (in $\mu \mathrm{mol} \mathrm{kg}^{-1}$ ), (g) absolute difference between observed and time response-corrected $\mathrm{O}_{2}$ as a measure of the time response bias for the Aanderaa 4330 optode (in $\mu \mathrm{mol} \mathrm{kg}{ }^{-1}$ ), and (h) absolute difference between observed and time response-corrected $\mathrm{O}_{2}$ as a measure of the time response bias for the SBE63 optode (in $\mu \mathrm{mol} \mathrm{kg}{ }^{-1}$ ).

sponse times (13-15 $\mu \mathrm{molkg}^{-1}$; Fig. 3g). After correction, both sensors agree to within $2-3 \mu \mathrm{mol} \mathrm{kg}{ }^{-1}$ (median difference) in the strongest gradient region $\left(120 \mu \mathrm{mol} \mathrm{kg}^{-1}\right.$ change over 8 min or $20 \mathrm{dbar}$ ) and better elsewhere (Fig. 3f). Especially near the surface and in the core of the oxygen minimum zone, the difference is close to zero. However, 
there is a residual pressure effect between the sensors of ca. $2 \mu \mathrm{mol} \mathrm{kg} \mathrm{kg}^{-1}$ at $2000 \mathrm{dbar}$ (Fig. 3f), in line with a pressure correction uncertainty of $0.3 \%$ per 1000 dbar for each of the two sensors (Bittig et al., 2015a).

This demonstrates that a time response correction is both useful for removing sensor artifacts (Fig. 3g, h) and feasible for both optode models, yielding highly consistent results (Fig. 3f). This is, however, only possible if the respective measurement times are known, i.e., provided by the manufacturer through the instrument's firmware as well as transmitted or stored in the data stream.

Interestingly, a similar analysis of the limited dataset of the third float, WMO ID 6900891, yields apparent boundary layer thicknesses $l_{\mathrm{L}}$ for the 4330 optode that are $100 \mu \mathrm{m}$ or more higher. We believe this is caused by growth of a biofilm on the sensing foil during its 5-week irregular near-surface drift, which artificially delays the time response. The SBE63 optode, being contained in the CTD's pumped path and antifouling regime, is probably better protected against such artifacts.

\section{In-air measurements}

The feasibility in calibrating $\mathrm{O}_{2}$ optodes on floats by measurements in-air, proposed by Körtzinger et al. (2005), was first demonstrated by Fiedler et al. (2013). Bittig and Körtzinger (2015) showed the first long time series of in-air measurements over 15 months using a single float. There, we demonstrated a systematic effect of any water-side oxygen disequilibrium on near-surface in-air measurements, which can and needs to be corrected. Subsequently, Johnson et al. (2015) confirmed the consistency between in-air and in situ calibrations for a fleet of floats, while Bushinsky et al. (2016) showed the utility of several in-air data acquisitions per surfacing, a daytime dependence, and the potential for in situ drift detection.

Bittig and Körtzinger (2015) used the then available ca. 15 months of data for float 6900890 . Here, we want to expand our analysis to all data until December 2016 and apply it to both dual-O $\mathrm{O}_{2}$ floats 6900889 and 6900890 (i.e., 25 and 38 months, respectively). Both floats show a similar "carry-over" slope $c$ of 0.23 , similar to Bittig and Körtzinger (2015) and Johnson et al. (2015). Using this value, we can compensate for the surface water contamination of the in-air measurements and derive an oxygen correction factor $m_{i}$ (or gain factor $g_{i}$ as in Johnson et al., 2015) for each profile $i$ (Fig. 4), where $p \mathrm{O}_{2, \text { obs }}$ is the uncalibrated optode $\mathrm{O}_{2}$ partial pressure (or $\mathrm{O}_{2}$ saturation or $\mathrm{O}_{2}$ concentration) and $p \mathrm{O}_{2 \text {,corr }}$ is the calibrated $\mathrm{O}_{2}$ :

$m=\frac{p \mathrm{O}_{2, \text { corr }}}{p \mathrm{O}_{2, \mathrm{obs}}}$.

In contrast to Bittig and Körtzinger (2015), the longer float time series confirm the results from Bushinsky et al. (2016),

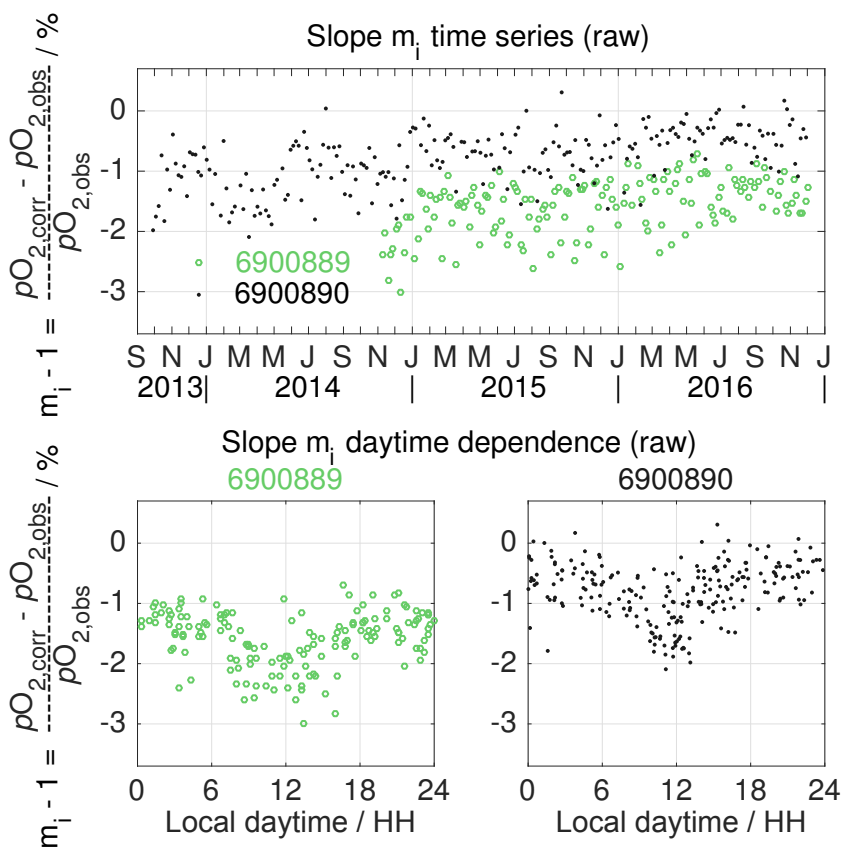

Figure 4. Time series (top) as well as daytime dependence (bottom) of the oxygen correction slope $m_{i}$ from in-air measurements for floats 6900889 (green circles) and 6900890 (black dots). $m_{i}$ was calculated for each in-air measurement by compensating for the surface water contamination with a uniform "carry-over" slope $c$ for the entire deployment. There is a trend towards higher correction factors $m_{i}$ with time, indicating a small drift of the optodes to lower sensitivity. Daytime has a noticeable effect on in-air measurements, with correction factors $m_{i}$ being decreased during the day by about $1 \%$, i.e., the optode readings being apparently increased. Both effects, the in situ drift and the daytime dependence, act in parallel and are superimposed in the data presented here.

i.e., the existence of a small but significant in situ drift of the optode (loss in $\mathrm{O}_{2}$ sensitivity of $0.27-0.40 \%$ per year) as well as a daytime dependence of the in-air measurements. Over the course of the day, correction factors decrease, i.e., optode in-air measurements apparently increase, by roughly $1 \%$ between 7 and $17 \mathrm{~h}$ local time, which is in the same direction but of slightly smaller magnitude than their findings (Fig. 5).

One can postulate that the daytime bias is related to solar heating of the sensor's sensing foil and thus the solar elevation angle $\theta$. In that case, the daytime effect $\Delta m_{i}$ would correlate on average with the cosine of the zenith angle (Eq. 4).

$\Delta m_{i}\left(\theta_{i}\right) \propto \cos \left(90^{\circ}-\theta_{i}\right)=\sin \theta_{i}$

If the bias is caused by the energy input to the float top cap, the daytime effect would be related to the direct Sun irradiance, which is a function of the sunlight's attenuation in the 


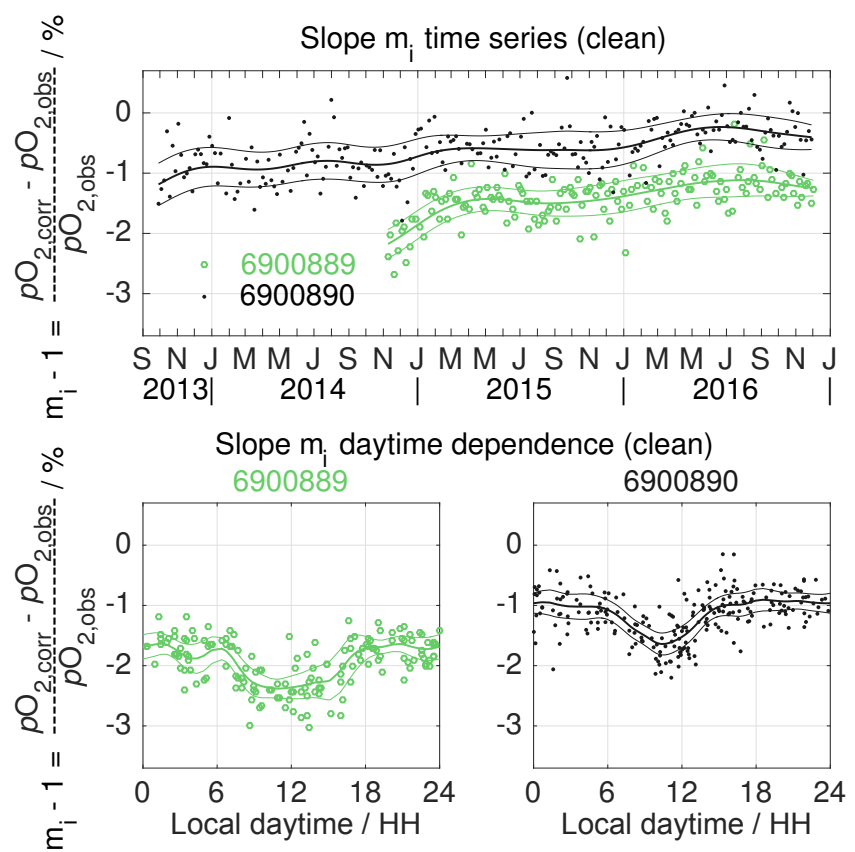

Figure 5. Same as Fig. 4 except that the daytime dependence was removed from the time series (Eq. 6, $\theta_{c}=15^{\circ}$; top panel) and the in situ drift removed from the daytime dependence (Eq. 7; bottom panel). Thick lines give a 6-month (time series) and $3 \mathrm{~h}$ (daytime dependence) low-pass filtered trend with $\pm 2 \sigma$ as thin lines. The $m_{i}$ low bias during midday is an important contributor to the average in-air correction (compare the time series of $m_{i}$ without and with compensation of the daytime dependence, Figs. 4 and 5, top panel, respectively) and needs to be considered.

atmosphere (Meinel and Meinel, 1976, Eq. 5),

$\Delta m_{i}\left(\theta_{i}\right) \propto 0.7^{\mathrm{AM}^{0.678}}$, with $\mathrm{AM}=$

$\sqrt{\left(\frac{6371}{9} \cdot \sin \theta_{i}\right)^{2}+2 \cdot \frac{6371}{9}+1}-\frac{6371}{9} \cdot \sin \theta_{i}$,

where AM is the air mass coefficient for the path length through the atmosphere, modeled as a spherical shell of $9 \mathrm{~km}$ around the Earth (radius $6371 \mathrm{~km}$ ). The data can be adequately described by both approaches. We thus used the solar elevation angle $\theta$ and the simpler Eq. (4) to parameterize the daytime dependence (Eq. 6),

$m_{i}\left(\theta_{i}\right)= \begin{cases}m_{0} & \theta_{i} \leq \theta_{c}, \\ m_{0}+m_{\mathrm{A}} \cdot \frac{\sin \theta_{i}-\sin \theta_{c}}{1-\sin \theta_{c}} & \theta>\theta_{c},\end{cases}$

where $\theta_{c}$ is the critical solar elevation angle below which correction factors $m_{i}$ are uniform and equal to $m_{0}$, and $m_{\mathrm{A}}$ is the amplitude of the midday bias. Based on the available data, we set $\theta_{c}$ to $15^{\circ}$. The in situ optode sensitivity drift is parameterized as a linear drift according to

$m_{i}\left(\Delta t_{i}\right)=m_{t=0}+a \cdot \frac{\Delta t_{i}}{365 \mathrm{~d}}$, where $\Delta t_{i}$ is the time since deployment (in days) for each profile $i$ and $a$ is the annual drift rate in $\% \mathrm{yr}^{-1}$. If enough data are available (as in our case), the linear carry-over (see Bittig and Körtzinger, 2015, Eq. 10), the daytime dependence (Eq. 6), and the in situ drift (Eq. 7) can be fit simultaneously (with fit parameters $c, m_{t=0}, m_{\mathrm{A}}$, and $a$ ) to correct all effects at once and obtain an optimal fit (Eq. 8).

$p \mathrm{O}_{2, \mathrm{obs}, i}^{\mathrm{infl}}=c \cdot p \mathrm{O}_{2, \mathrm{obs}, i}^{\mathrm{defl}}+\frac{1-c}{m_{i}\left(\theta_{i}, \Delta t_{i}\right)} \cdot p \mathrm{O}_{2, \mathrm{air}, i}$

Consequently, data can be corrected by

$$
\begin{aligned}
& p \mathrm{O}_{2, \mathrm{corr}, i}=m_{i}\left(\theta_{i}, \Delta t_{i}\right) \cdot p \mathrm{O}_{2, \mathrm{obs}, i}= \\
& \left\{\begin{array}{l}
\left(m_{t=0}+a \cdot \frac{\Delta t_{i}}{365 \mathrm{~d}}\right) \cdot p \mathrm{O}_{2, \mathrm{obs}, i} \quad \theta_{i} \leq \theta_{c} \\
\left(\begin{array}{l}
\left.m_{t=0}+a \cdot \frac{\Delta t_{i}}{365 \mathrm{~d}}+m_{\mathrm{A}} \cdot \frac{\sin \theta_{i}-\sin \theta_{c}}{1-\sin \theta_{c}}\right) \cdot p \mathrm{O}_{2, \mathrm{obs}, i} \quad \theta>\theta_{c}
\end{array}\right.
\end{array}\right.
\end{aligned}
$$

For simple calibration, however, preference should be given to dusk, nighttime, and dawn measurements $\left(\theta_{i} \leq \theta_{c}\right)$, where the (as yet uncharacterized) amplitude $m_{\mathrm{A}}$ of the daytime dependence is irrelevant (Eq. 6).

For float $6900889, m_{\mathrm{A}}$ is ca. $0.8 \%$, while it is around $0.5 \%$ for float 6900890 (Table 1). Both floats show a significant in situ drift: $\mathrm{O}_{2}$ levels decrease by -0.40 and $-0.27 \% \mathrm{yr}^{-1}$, respectively, with the $95 \%$ confidence level being around $0.11 \% \mathrm{yr}^{-1}$ after 2 years of float data and around $0.06 \% \mathrm{yr}^{-1}$ after 3 years. The "carry-over" slope $c$ of float 6900889 , operating in open ocean waters, is not as tightly constrained as for 6900890 , operating closer to coastal and upwelled waters, where the range of oxygen supersation and undersaturation is larger. When accounting for the surface water "carry-over" effect only, fit root mean squared errors (RMSEs) are around $0.8 \mathrm{mbar}$ (Bittig and Körtzinger, 2015). With all effects included, the RMSE is reduced to $0.5 \mathrm{mbar}$. The intercept $m_{t=0}$ gives an indication of the uncertainty in $m_{i}$ after daytime and drift correction, which is on the order of $0.1 \%$.

To evaluate the sensitivity to the atmospheric reanalysis product, air $p \mathrm{O}_{2}$ was derived from NCEP/NCAR (Kalnay et al., 1996), ERA-Interim (Dee et al., 2011), MERRA-2 (Rienecker et al., 2011), and JRA-55 (Harada et al., 2016) reanalysis data. ERA-Interim has a delay of 2-3 months, so the analysis was limited to all profiles until September 2016 (Table 1). Differences in $m_{t=0}$ are up to $0.1-0.2 \%$ depending on the reanalysis model and as such on the same order of magnitude as the uncertainty of the calculation. This should be considered when assessing the absolute calibration accuracy of in-air data. Differences for $c, m_{\mathrm{A}}$, and $a$ are within their confidence intervals.

\section{Optode stability}

Based on regular in-air measurements, the Aanderaa 4330 optodes show a significant drift of -0.40 and $-0.27 \% \mathrm{yr}^{-1}$ for floats 6900889 and 6900890 , respectively. This is in a 
Table 1. Simultaneous fit of "carry-over" slope $c$, initial $\mathrm{O}_{2}$ correction factor $m_{t=0}$ relative to the deployment calibration, daytime dependence amplitude $m_{\mathrm{A}}$, and annual drift rate $a$ (Eq. 8) for floats 6900889 and 6900890 using air $p \mathrm{O}_{2}$ derived from different reanalysis models. The analysis was limited to all profiles until the most recently available ERA-Interim date, i.e., September 2016.

\begin{tabular}{|c|c|c|c|c|c|}
\hline Float & Reanalysis & $c$ & $m_{t=0}=\left.\frac{p \mathrm{O}_{2, \text { corr }}}{p \mathrm{O}_{2, \text { deploy }}}\right|_{t=0}$ & $m_{\mathrm{A}}$ in $\%$ & $a$ in $\% \mathrm{yr}^{-1}$ \\
\hline \multirow[t]{4}{*}{6900889} & NCEP/NCAR & $0.21(0.05)$ & $0.9821(0.0012)$ & $-0.79(0.15)$ & $+0.42(0.11)$ \\
\hline & ERA-Interim & $0.22(0.04)$ & $0.9836(0.0011)$ & $-0.79(0.15)$ & $+0.40(0.11)$ \\
\hline & MERRA2 & $0.23(0.05)$ & $0.9839(0.0013)$ & $-0.81(0.17)$ & $+0.36(0.12)$ \\
\hline & JRA-55 & $0.24(0.04)$ & $0.9838(0.0012)$ & $-0.93(0.16)$ & $+0.40(0.11)$ \\
\hline \multirow[t]{4}{*}{6900890} & NCEP/NCAR & $0.23(0.02)$ & $0.9899(0.0012)$ & $-0.53(0.13)$ & $+0.24(0.06)$ \\
\hline & ERA-Interim & $0.23(0.02)$ & $0.9894(0.0012)$ & $-0.58(0.13)$ & $+0.29(0.05)$ \\
\hline & MERRA2 & $0.21(0.02)$ & $0.9905(0.0012)$ & $-0.49(0.13)$ & $+0.25(0.06)$ \\
\hline & JRA-55 & $0.24(0.02)$ & $0.9894(0.0012)$ & $-0.54(0.13)$ & $+0.29(0.06)$ \\
\hline
\end{tabular}

$95 \%$ confidence interval given in brackets; $\theta_{c}=15^{\circ}$
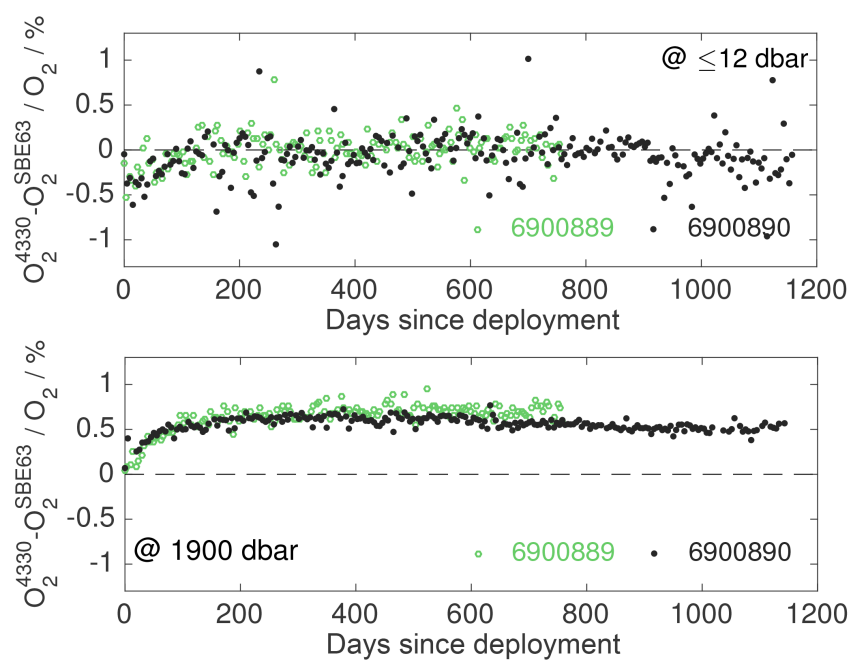

Figure 6. Percent difference between $\mathrm{O}_{2}$ from the Aanderaa 4330 optode and the SBE63 optode using time response corrected data (top) near the surface and (bottom) at depth for floats 6900889 (green) and 6900890 (black). There seems to be a conditioning effect on either one or both optodes during the first half-year $/ \approx 40$ profiles, after which differences between optodes are stable.

similar range for in situ drift as reported by Bushinsky et al. (2016) for 10-12 out of 14 optodes. In contrast, Johnson et al. (2015) observed both significant positive and negative drifts for individual floats, but seen over a fleet of 29 floats, this drift was indistinguishable from zero. However, they did not correct explicitly for the carry-over effect but, given that $\mathrm{O}_{2}$ is typically less than $3 \%$ supersaturated, assumed it to be negligible as long as the data record spans at least a full year.

Since the SBE63 optode on floats can not measure oxygen in-air, a direct comparison with in-air measurements is not possible. However, it can be done indirectly via the difference between the 4330 and SBE63 optodes (Fig. 6), both near the surface within the mixed layer as well as at depth (1900 dbar). The SBE63s have been in situ calibrated against the 4330 optodes near the surface, so differences cluster around zero with a standard deviation of $0.2 \%$. At depth, however, there is a difference between both on the order of $0.5 \%$, which we attribute to uncertainties in the pressure correction (Bittig et al., 2015a).

Moreover, at both depths, there seems to be a conditioning effect during the first half-year ( $\approx 40$ profiles) only after which the difference between both sensors stabilizes. Since we can only discuss the difference, this can be caused by either one or both sensors. Reasons could be repeated pressure cycling, removal of surface films or contaminants from the sensing foils, or others, and the exact cause remains speculative. However, we recommend that users critically evaluate their optode data regarding whether they see such a conditioning artifact, too.

Linear fit slopes of the sensor difference (using only data after 180 days) for the two floats are indistinguishable from zero within \pm 0.06 and $\pm 0.04 \% \mathrm{yr}^{-1}$ (95\% CI), respectively. This implies that the SBE63 optodes drift as much as the 4330 optodes and suggests that in situ drift is governed by environmental factors. Concerning the different in situ drift rates between the two floats, the only obvious difference is that the second pair of optodes was deployed a year later and subjected to a second laboratory calibration before deployment. Otherwise, they were from the same batch, treated the same, and the floats were deployed in comparable field conditions.

\section{Conclusions}

A slow $\mathrm{O}_{2}$ time response reduces fine-scale resolution and causes a lag between in situ and observed $\mathrm{O}_{2}$ profiles. It is important for data users to assess and quantify the impact on $\mathrm{O}_{2}$ data quality, as the effect can be substantial for the analysis (e.g., Plant et al., 2016). However, as demonstrated by Bittig et al. (2014) and here, it is feasible to correct for the time response effect on slowly moving, buoyancy-driven 
platforms. In this work, we refine the flow regime required for such corrections for floats and gliders and summarize the procedure for time response corrections (from Bittig et al., 2014). Reconstruction, however, is only possible if measurement times are known. These need to be provided by the instrument's firmware/manufacturer as well as be transmitted and stored with the original profile data. Of course, every correction introduces uncertainty, so the ideal case would be a fast (and accurate) $\mathrm{O}_{2}$ sensor that does not need time response correction.

In-air measurements at every surfacing of Argo- $\mathrm{O}_{2}$ floats prove to be an ideally suited means to check and correct a change (or loss) in $\mathrm{O}_{2}$ sensitivity of optodes, the primary reason for $\mathrm{O}_{2}$ optode drift (Bittig and Körtzinger, 2015). As such, they allow one to correct both sensor drift between calibration and deployment (several \% magnitude) as well as sensor drift in situ during deployment (order of $-0.5 \% \mathrm{yr}^{-1}$ ). In detail, measurements in air close to the sea surface are not purely $100 \%$ air, as one would expect under controlled, stable conditions. Most importantly, any waterside oxygen disequilibrium has a systematic effect on nearsurface in-air measurements, which can and needs to be corrected. In addition, midday observations are offset with respect to nighttime or dusk and dawn measurements, such that a failure to account for the daytime effect introduces a systematic bias. While its mechanistic origin is still unclear, the data suggest a relation to solar heating. Despite these secondary effects, any float $\mathrm{O}_{2}$ data calibrated with regular in-air measurements are more accurate than without in-air measurements (compare Takeshita et al., 2013), but neglecting the water-side "carry-over" or daytime effect should be avoided as good practice.
Based on regular in-air measurements over 38 and 25 months, respectively, we were able to detect a significant in situ drift in both 4330 optodes of -0.27 and $-0.40 \% \mathrm{yr}^{-1}$, respectively. The SBE63 optodes' in situ stability is comparable to the one of the 4330 optodes.

Given the findings of several studies on both optode "storage" drift and in situ drift, we strongly propose that every Biogeochemical-Argo float be deployed with in situ $\mathrm{O}_{2}$ optode in-air measurements (Bittig et al., 2015b). Float principal investigators (PIs) need to ensure with manufacturers that their floats provide this capability.

To our knowledge, the feasibility of in-air measurements on gliders still needs to be shown. Given the generally shorter deployment periods and, more importantly, the possibility of careful pre- and post-deployment calibration/drift characterization (e.g., by optode in-air measurements under controlled conditions on deck), it might not be necessary to have in situ in-air measurements on gliders.

\section{Data availability}

The float data are made freely available by the International Argo Program (Argo, 2000) and the national programs that contribute to it (http://www.argo.ucsd.edu,http:// argo.jcommops.org). The Argo Program is part of the Global Ocean Observing System. NCEP Reanalysis data provided by the NOAA/OAR/ESRL PSD, Boulder, Colorado, USA, from their website at http://www.esrl.noaa.gov/psd/, ERAInterim data provided courtesy of ECMWF, MERRA2 data files acquired from the Goddard Earth Science Data Information Services Center (GES DISC), and JRA-55 data provided from the Japanese 55-year Reanalysis (JRA-55) project carried out by the Japan Meteorological Agency (JMA). 


\section{Appendix A: Time response correction}

Here, we reproduce the essential equations from Bittig et al. (2014) for the correction of the optode time response as demonstrated in Sect. 3, give an explicit parameterization for the flow-boundary layer thickness relation for optodes in pumped mode of operation, and provide the two-layer diffusional model data to relate boundary layer thickness, temperature, and response time for interpolation as supplemental material. We hope this will be more useful than the solely graphical representation of Bittig et al. (2014).

The $\mathrm{O}_{2}$ optode's time response is governed by the diffusion of $\mathrm{O}_{2}$ in/out of the sensing foil and through the liquid boundary layer in front of the sensing foil. In fact, the boundary layer is responsible for most of the "lag". The step response follows (approx.) an exponential curve. The continuous time response equals a single-pole low-pass filter of the in situ $\mathrm{O}_{2}$ time series. In discrete form using the bilinear transformation, this filter is recursively described by

$c^{\mathrm{obs}}\left(t_{i+1}\right)=a \cdot c^{\mathrm{obs}}\left(t_{i}\right)+b \cdot\left(c^{\mathrm{in}-\mathrm{situ}}\left(t_{i+1}\right)+c^{\mathrm{in}-\mathrm{situ}}\left(t_{i}\right)\right)$,

$a=1-2 b, \quad b=\left(1+2 \frac{\tau}{t_{i+1}-t_{i}}\right)^{-1}$,

$c^{\mathrm{obs}}\left(t_{i=0}\right)=c^{\mathrm{in}-\mathrm{situ}}\left(t_{i=0}\right)$,

where $c^{\text {in-situ }}$ is the true in situ $\mathrm{O}_{2}$ time series, $c^{\text {obs }}$ the $\mathrm{O}_{2}$ time series of the optode, and $\tau$ the response time for the interval between $t_{i}$ and $t_{i+1}$. The initial condition (Eq. A2) assumes an equilibrated optode, which can be adjusted according to the application.

For the reconstruction, Eq. (A1) is rearranged to

$\frac{c^{\mathrm{in}-\mathrm{situ}}\left(t_{i+1}\right)+c^{\mathrm{in}-\mathrm{situ}}\left(t_{i}\right)}{2}=\frac{1}{2 b} \cdot\left(c^{\mathrm{obs}}\left(t_{i+1}\right)-a \cdot c^{\mathrm{obs}}\left(t_{i}\right)\right)$,

$a=1-2 b, \quad b=\left(1+2 \frac{\tau}{t_{i+1}-t_{i}}\right)^{-1} ;$

i.e., knowledge of the optode time series (measurement times, $t_{i}$, and optode readings, $c^{\text {obs }}$ ) as well as the response time (series) $\tau$ yields a time series of the consecutive means of the true in situ time series (left side of Eq. A3). For this operation, no initial condition of the filter is required. To obtain the in situ time series at the original sampling times $t_{i}$, the time series of consecutive means obtained from Eq. (A3) needs to be interpolated to $t_{i}$.
For a pumped optode, the relation between flow $\dot{V}$ and boundary layer thickness $l_{\mathrm{L}}$ is described (following experiment 1, Bittig et al., 2014) by

$l_{\mathrm{L}}$ (pumped) $/ \mu \mathrm{m}=1.8 \times 10^{4} \cdot \frac{1}{\dot{V} / \mathrm{mL} \mathrm{min}^{-1}}+4$,

with an uncertainty of the greater of $4 \mu \mathrm{m}$ or $10 \%$. For unpumped optodes on fast profiling platforms, i.e., CTDs, the vertical velocity $v$-boundary layer thickness $l_{\mathrm{L}}$ relation depends to a large extent on the mode and orientation of attachment (see the difference between experiment Eqs. 5 and 6 , Bittig et al., 2014) with a range of $l_{\mathrm{L}}$ (CTD) from 20 to $55 \mu \mathrm{m}$ ( $1 \sigma$ from 5 to $35 \mu \mathrm{m})$. For slowly profiling platforms, we suggest using Eq. (1) for floats and Eq. (2) for gliders. They might need adjustments depending on the actual optode attachment or mode of operation.

The boundary layer thickness $l_{\mathrm{L}}$ can be converted to a response time $\tau$ using the sensing membrane thickness $l_{\mathrm{M}}$ of the respective optode model, the two-layer diffusional model of Bittig et al. (2014), and temperature $T$. For the SBE63 optode, we used $l_{\mathrm{M}}=130 \mu \mathrm{m}$, for the Aanderaa 3830/4330 optode with standard foil $100 \mu \mathrm{m}$, and for the Aanderaa 4330F optode with fast response foil $50 \mu \mathrm{m}$. Results for the latter two were shown in figure 11, Bittig et al. (2014). Here, the same model data of $\tau$ against $l_{\mathrm{L}}$ and $T$ can be found for all three optode sensing foils in the supplemental material. 


\section{The Supplement related to this article is available online at doi:10.5194/os-13-1-2017-supplement.}

Acknowledgement. The authors want to thank Patrice Brehmer (IRD, Dakar, Senegal) as well as the captain and crew of $\mathrm{M} / \mathrm{V}$ Samba Laobé Fall cruise AWARGO for help with the deployment of 6900890, Tobias Hahn (GEOMAR, Kiel, Germany), as well as the captain, crew, and scientists of R/V Polarstern cruise PS88.2 for the deployment of 6900889, and Sea-Bird Electronics for their efforts with float and firmware customization. Financial support by the following projects is gratefully acknowledged: AtlantOS (EU Horizon 2020 grant agreement 2014-633211), remOcean (EU ERC grant agreement 246777), and E-AIMS (EU FP7 project 312642), as well as $\mathrm{O}_{2}$-Floats (KO 1717/3-1) and the SFB754 of the German Science Foundation (DFG).

Edited by: O. Zielinski

Reviewed by: three anonymous referees

\section{References}

Argo: Argo float data and metadata from Global Data Assembly Centre (Argo GDAC), doi:10.17882/42182, 2000.

Bittig, H. C. and Körtzinger, A.: Tackling oxygen optode drift: Near-surface and in-air oxygen optode measurements on a float provide an accurate in situ reference, J. Atmos. Ocean. Tech., 32, 1536-1543, doi:10.1175/JTECH-D-14-00162.1, 2015.

Bittig, H. C., Fiedler, B., Steinhoff, T., and Körtzinger, A.: A novel electrochemical calibration setup for oxygen sensors and its use for the stability assessment of Aanderaa optodes, Limnol. Oceanogr., 10, 921-933, doi:10.4319/lom.2012.10.921, 2012.

Bittig, H. C., Fiedler, B., Scholz, R., Krahmann, G., and Körtzinger, A.: Time response of oxygen optodes on profiling platforms and its dependence on flow speed and temperature, Limnol. Oceanogr., 12, 617-636, doi:10.4319/lom.2014.12.617, 2014.

Bittig, H. C., Fiedler, B., Fietzek, P., and Körtzinger, A.: Pressure Response of Aanderaa and Sea-Bird Oxygen Optodes, J. Atmos. Ocean. Tech., 32, 2305-2317, doi:10.1175/JTECH-D-150108.1, 2015a.

Bittig, H. C., Körtzinger, A., Johnson, K. S., Claustre, H., Emerson, S., Fennel, K., Garcia, H., Gilbert, D., Gruber, N., Kang, D.-J., Naqvi, W., Prakash, S., Riser, S., Thierry, V., Tilbrook, B., Uchida, H., Ulloa, O., and Xing, X.: SCOR WG 142: Recommendation for Oxygen Measurements from Argo Floats: Implementation of In-Air-Measurement Routine to Assure Highest Long-term Accuracy, doi:10.13155/45917, 2015 b.

Bushinsky, S. M., Emerson, S. R., Riser, S. C., and Swift, D. D.: Accurate oxygen measurements on modified Argo floats using in situ air calibrations, Limnol. Oceanogr., 14, 491-505, doi:10.1002/lom3.10107, 2016.

D'Asaro, E. A. and McNeil, C.: Calibration and Stability of Oxygen Sensors on Autonomous Floats, J. Atmos. Ocean. Tech., 30, 1896-1906, doi:10.1175/JTECH-D-12-00222.1, 2013.

Dee, D. P., Uppala, S. M., Simmons, A. J., Berrisford, P., Poli, P., Kobayashi, S., Andrae, U., Balmaseda, M. A., Balsamo, G.,
Bauer, P., Bechtold, P., Beljaars, A. C. M., van de Berg, L., Bidlot, J., Bormann, N., Delsol, C., Dragani, R., Fuentes, M., Geer, A. J., Haimberger, L., Healy, S. B., Hersbach, H., Hólm, E. V., Isaksen, L., Kållberg, P., Köhler, M., Matricardi, M., McNally, A. P., Monge-Sanz, B. M., Morcrette, J.-J., Park, B.-K., Peubey, C., de Rosnay, P., Tavolato, C., Thépaut, J.-N., and Vitart, F.: The ERA-Interim reanalysis: configuration and performance of the data assimilation system, Q. J. Roy Meteorol. Soc., 137, 553597, doi:10.1002/qj.828, 2011.

Fiedler, B., Fietzek, P., Vieira, N., Silva, P., Bittig, H. C., and Körtzinger, A.: In Situ $\mathrm{CO}_{2}$ and $\mathrm{O}_{2}$ Measurements on a Profiling Float, J. Atmos. Ocean. Tech., 30, 112-126, doi:10.1175/JTECH-D-12-00043.1, 2013.

Harada, Y., Kamahori, H., Kobayashi, C., Endo, H., Kobayashi, S., Ota, Y., Onoda, H., Onogi, K., Miyaoka, K., and Takahashi, K.: The JRA-55 Reanalysis: Representation of Atmospheric Circulation and Climate Variability, J. Meteor. Soc. Jp., 94, 269-302, doi:10.2151/jmsj.2016-015, 2016.

Johnson, K. S. and Claustre, H.: Bringing Biogeochemistry into the Argo Age, Eos, 97, doi:10.1029/2016EO062427, 2016.

Johnson, K. S., Plant, J. N., Riser, S. C., and Gilbert, D.: Air Oxygen Calibration of Oxygen Optodes on a Profiling Float Array, J. Atmos. Ocean. Tech., 32, 2160-2172, doi:10.1175/JTECH-D15-0101.1, 2015.

Kalnay, E., Kanamitsu, M., Kistler, R., Collins, W., Deaven, D., Gandin, L., Iredell, M., Saha, S., White, G., Woollen, J., Zhu, Y., Leetmaa, A., Reynolds, R., Chelliah, M., Ebisuzaki, W., Higgins, W., Janowiak, J., Mo, K. C., Ropelewski, C., Wang, J., Jenne, R., and Joseph, D.: The NCEP/NCAR 40-Year Reanalysis Project, Bull. Am. Meteor. Soc., 77, 437-471, doi:10.1175/15200477(1996)077<0437:TNYRP>2.0.CO;2, 1996.

Körtzinger, A., Schimanski, J., and Send, U.: High Quality Oxygen Measurements from Profiling Floats: A Promising New Technique, J. Atmos. Ocean. Tech., 22, 302-308, doi:10.1175/JTECH1701.1, 2005.

Meinel, A. B. and Meinel, M. P.: Applied Solar Energy: An Introduction, Addison-Wesley Pub. Co, 1976.

Plant, J. N., Johnson, K. S., Sakamoto, C. M., Jannasch, H. W., Coletti, L. J., Riser, S. C., and Swift, D. D.: Net community production at Ocean Station Papa observed with nitrate and oxygen sensors on profiling floats, Global Biogeochem. Cy., 30, 859879, doi:10.1002/2015GB005349, 2016.

Rienecker, M. M., Suarez, M. J., Gelaro, R., Todling, R., Bacmeister, J., Liu, E., Bosilovich, M. G., Schubert, S. D., Takacs, L., Kim, G.-K., Bloom, S., Chen, J., Collins, D., Conaty, A., da Silva, A., Gu, W., Joiner, J., Koster, R. D., Lucchesi, R., Molod, A., Owens, T., Pawson, S., Pegion, P., Redder, C. R., Reichle, R., Robertson, F. R., Ruddick, A. G., Sienkiewicz, M., and Woollen, J.: MERRA: NASA's Modern-Era Retrospective Analysis for Research and Applications, J. Clim., 24, 3624-3648, doi:10.1175/JCLI-D-11-00015.1, 2011.

Sea-Bird Electronics: SBE 41/41CP CTD Module for Autonomous Profiling Floats (Argo), http://www.seabird.com/sbe41-argo-ctd, last access: 2 August 2016.

Takeshita, Y., Martz, T. R., Johnson, K. S., Plant, J. N., Gilbert, D., Riser, S. C., Neill, C., and Tilbrook, B.: A climatology-based quality control procedure for profiling float oxygen data, J. Geophys. Res.-Oceans, 118, 5640-5650, doi:10.1002/jgrc.20399, 2013. 
Tengberg, A., Hovdenes, J., Andersson, H. J., Brocandel, O., Diaz, R., Hebert, D., Arnerich, T., Huber, C., Körtzinger, A., Khripounoff, A., Rey, F., Ronning, C., Schimanski, J., Sommer, S., and Stangelmayer, A.: Evaluation of a lifetime-based optode to measure oxygen in aquatic systems, Limnol. Oceanogr., 4, 7-17, doi:10.4319/lom.2006.4.7, 2006

Testor, P., Mortier, L., Karstensen, J., Mauri, E., Heywood, K. J., Hayes, D., Alenius, P., Alvarez, A., Barrera, C., Beguery, L., Bernardet, K., Bertino, L., Beszczynska-Müller, A., Carval, T., Counillon, F., Dumont, E., Griffiths, G., Haugan, P. M., Kaiser, J., Kasis, D., Krahmann, G., Llinas, O., Merckelbach, L., Mourre, B., Nittis, K., Onken, R., D’Ortenzio, F., Pouliquen, S., Proelß, A., Riethmüller, R., Ruiz, S., Sherwin, T., Smeed, D., Stemmann, L., Tikka, K., and Tintore, J.: EGO: towards a global glider infrastructure for the benefit of marine research and operational oceanography, Mercator Ocean - CORIOLIS Quarterly Newsletter, 12-15, http://archimer.ifremer.fr/doc/00114/22554/ (14 September 2016), 2012.
Uchida, H., Kawano, T., Kaneko, I., and Fukasawa, M.: In Situ Calibration of Optode-Based Oxygen Sensors, J. Atmos. Ocean. Tech., 25, 2271-2281, doi:10.1175/2008JTECHO549.1, 2008. 